\title{
Target-based molecular signature characteristics of cervical adenocarcinoma and squamous cell carcinoma
}

\author{
YONG-WAN KIM ${ }^{1}$, SU MI BAE ${ }^{1}$, YONG WOOK KIM ${ }^{2}$, DONG CHOON PARK ${ }^{3}$, KEUN-HO LEE ${ }^{3}$, \\ HAI-BO LIU ${ }^{1}$, IN-WOOK KIM ${ }^{1}$, CHUN KEUN JANG ${ }^{1}$ and WOONG SHICK AHN ${ }^{3}$ \\ ${ }^{1}$ Catholic Research Institutes of Medical Science, ${ }^{2}$ Department of Obstetrics and Gynecology, College of Medicine, \\ Catholic University of Korea, Incheon St. Mary's Hospital, Incheon; ${ }^{3}$ Department of Obstetrics and Gynecology, \\ College of Medicine, The Catholic University of Korea, Seoul, Republic of Korea
}

Received July 27, 2012; Accepted October 15, 2012

DOI: $10.3892 /$ ijo.2013.1961

\begin{abstract}
There is an urgent need for molecular marker studies of adenocarcinoma (AC) and squamous cell carcinoma (SCC) of the uterine cervix. This study utilized oligomicroarray and pathway analyses to characterize a transcriptomic signature with molecular networks associated with AC and SCC. A $10 \mathrm{~K}$ oligomicroarray was used to identify potential transcripts that were differentially expressed in cervical cancers from 28 patients and common reference RNAs from 17 different normal cervixes. Molecular networks were correlated using genomics tools to globally explore cellular pathways. Gene expression levels of 46 transcripts separated cancer samples into AC and SCC groups. Genes including: KRT17, IGFBP2, CALCA and VIPR1 were differentially expressed in AC and SCC. In addition, we identified a transcriptomic signature that predicted tumor classification and progression based upon its cellular processes. The downregulated signatures for SCC were cell death of pheochromocytoma cells $(\mathrm{P}=0.0037)$, apoptosis of neurons $(\mathrm{P}=0.009)$ and damage to DNA $(\mathrm{P}=0.0038)$. By contrast, the upregulated molecular signatures in $\mathrm{AC}$ were immunological disorder $(\mathrm{P}=0.006)$, splenomegaly $(\mathrm{P}=0.0053)$ and hepatic system disorder $(\mathrm{P}=0.006)$. The $\mathrm{G} 2 / \mathrm{M}$ DNA damage checkpoint regulation pathway $(\mathrm{P}=0.05)$ was found to be significantly linked to IGF1R as a new regulatory component of a putative cytoplasmic signaling cascade in SCC. By contrast, the antigen presenting canonical pathway $(\mathrm{P}=0.038)$ appeared to be linked to PPAR $\gamma$ in AC. Taken together, these experiments provide important new information regarding the role of molecular networks in mediating SCC and AC, possibly through two independent pathways, and contribute to provide new targets for the prevention and treatment of cervical cancer.
\end{abstract}

Correspondence to: Dr Woong Shick Ahn, Department of Obstetrics and Gynecology, College of Medicine, The Catholic University of Korea, Seoul, Republic of Korea

E-mail:ahnlab1@catholic.ac.kr

Key words: squamous cell carcinoma, adenocarcinoma, cervical cancer, molecular interaction networks, microarray analysis

\section{Introduction}

Invasive cervical cancer can be divided in two major histological types: squamous cell carcinoma (SCC) and adenocarcinoma (AC). Although the incidence of SCC of the uterine cervix has been decreasing, that of cervical adenocarcinoma (AC) has been increasing in recent years (1). Compared with SCC, AC of the cervix is rare. Due to the relative rarity, only a few large studies have addressed risk factors in adenocarcinoma (2). Previous epidemiologic studies of the association between human papillomavirus (HPV) and cervical adenocarcinoma have shown strong associations; this information has suggested that there appears to be a difference in HPV types and prevalence (3). In SCC, HPV 16 is the dominant type, while in adenocarcinoma, HPV 18 is seen more frequently (4). However, the preference and capability of HPV 18 above HPV 16 to infect and transform glandular epithelial cells is unclear (3). Some evidence indicates that cofactors that contribute to the progression of HPV-infected cervical cells to $\mathrm{AC}$ are distinct from those that contribute to the progression to squamous cell carcinoma (5). Smoking, for example, is associated with an increased risk for SCC but there is no association for $\mathrm{AC}$ (6). Although several factors have been established as important initial events for the tumorigenesis of cervical carcinoma, the reports regarding the molecular biology involved in the cellular process are rare. Only a few studies have been published comparing global transcript expressions for both tumor types (7). A major limitation of these studies is the fact that no adjustment for the molecular pathogenesis has been made.

In this study, we used oligomicroarray technology and pathway analyses to describe the role of molecular networks in the development of AC and SCC. Evaluations were carried out using bioinformatic analysis of genomic data from expression patterns of genes with emphasis on network and pathway analysis. The expression profiles were histology-dependent and clearly differentiated. Therefore, the expression of the genes in this study clearly displayed evidence indicating similarities and differences between the molecular environments in AC and SCC. Our findings also have important implications for the diagnostic and possible therapeutic intervention of patients with cervical cancer as well as future research. 


\section{Materials and methods}

Ethics statement. All patients involved in the study signed a declaration of consent stating that the patients specimens may be used for scientific intentions. Specimens were obtained from the patients in the Department of Obstetrics and Gynecology in concordance with procedures approved by the Institutional Review Board of The Catholic University of Korea (06BR131).

Tissue samples. The disease status was assigned according to the International Federation of Gynecology and Obstetrics. Briefly, all patients were Korean. Of the 28 patients with cervical cancer, 11 patients were classified as $\mathrm{AC}$ and 17 patients were classified as SCC. Normal cervix samples were obtained from 17 uterine leiomyoma patients and stored in liquid nitrogen. Common reference RNAs from 17 different normal cervixes were used as a consistent control. All samples were filled up to a depth of $1-2 \mathrm{~mm}$ using a microscope, carefully avoiding the underlying stromal tissue. The results were then examined with the microscope. The samples were immediately placed in vials containing $2 \mathrm{ml}$ TRIzol (Gibco-BRL, Grand Island, NY), stored at $4^{\circ} \mathrm{C}$ for up to $12 \mathrm{~h}$, and then frozen at $-80^{\circ} \mathrm{C}$.

Probe hybridization. Reverse transcription was carried out using total RNA isolated from samples using TRIzol. Experimental procedures for microarray assay were performed according to the Macrogen Magic II-10K technical manual. Total RNA was converted into double stranded cDNA using the cDNA synthesis system (Roche) using a T7-(dT) 24 primer. The fluorescent labeled-cDNA was hybridized with Magic II-10K microarray (Macrogen, Seoul, Korea) for $16 \mathrm{~h}$ at $42^{\circ} \mathrm{C}$. Arrays were then washed and scanned with a GenePix 4000B scanner (Axon Instruments, Union City, CA). Each chip contained a total of 10,368 elements of which 10,108 were unique genes/clusters.

Western blot analysis. The proteins were electrophoresed for $2 \mathrm{~h}$ with SDS-PAGE and western blotting was performed for $1 \mathrm{~h}$ and 30 min with a Hybond-ECL membrane (Amersham, Uppsala, Sweden) at $100 \mathrm{~V}$. Protein bands were visualized using an ECL kit according to the manufacturer's protocol (Amersham, Arlington Heights, IL).

Analysis. Acquired images were processed and analyzed statistically for interpretation of the analyzed spot intensity results using Imagene v4.1 software (Roche). Non-biological factors that contributed to variability of data were minimized using global normalization/scaling with data from all probe sets; normalization for the microarrays was also carried out. For each gene, its relative fold change in expression was the ratio of the sum of the median expression levels of cervical cancer tissues compared to the common control. Genes were excluded from the analysis if their expression was negative or if they were too smeared to read. Genes that showed differences in their expression levels, of at least 2.0 -fold, were selected for the different analyses (hierarchical cluster analysis, functional cluster analysis and biological pathway analysis). Supervised hierarchical clustering was performed in clusters and a two-way average linkage clustering was applied. To classify the observed profiles of gene expression, functional analysis was carried out as follows. Each gene was annotated by integrating the information (as of October, 2011) on the Gene Ontology website (http://GenMapp.org). First, each gene was associated with its corresponding current curated gene entry in UniGene (http://www.ncbi.nlm.nih. gov). Next, the Ingenuity Pathway Analysis software (IPA, Ingenuity Systems, Mountain View, CA) was utilized to identify networks of interacting genes and other functional groups. Semantically consistent pathway relationships were modeled based on a continual, formal extraction from the public domain literature and covered $>10,400$ human genes (www.ingenuity.com/products/pathways_knowledge.html). These genes were then used as a starting point for generating biologic networks. The resulting networks are presented in a graphic format.

Statistical analysis. Statistical analysis was done using $\chi^{2}$ test and ANOVA. Values from the different groups were compared. A P-value $<0.05$ was considered significant.

\section{Results}

Hierarchical cluster analysis. Using unsupervised hierarchical clustering, by average linkage analysis, we successfully grouped AC and SCC into 2 distinctive groups (Fig. 1A). Gene expression levels of 46 transcripts separated hierarchical clustering samples into 2 groups on the basis of the expression patterns. These data are represented by a dendrogram with the closest branches of the tree representing arrays with similar gene expression patterns. The results showed that there was a significant difference between AC and SCC. Even though the overall signal patterns found on the AC and SCC hybridized arrays were similar, a small subset of 46 transcripts show differential expression signals in comparisons between the $\mathrm{AC}$ and SCC samples. These genes can be characterized as new putative histology-specific cervical cancer genes. Among genes significantly upregulated in AC, we have found VIPR1, NIFUN, SPEN, MAD and BCL3 of particular interest. The genes upregulated in SCC included KRT17, CALCA and CHMP2A. KRT17 is one of the pathological situation genes that are expressed only in pathological situations such as metaplasia and carcinoma of the uterine cervix as well as in psoriasis vulgaris. Western blots were performed to confirm gene expression patterns in this study. As shown in Fig. 1B, several up- and downregulated proteins confirmed the patterns obtained from the microarray and showed the consistency of the assays.

Functional cluster analysis. To show how the transcripts, identified by the gene expression signature, were related in $\mathrm{AC}$ and SCC, we placed the transcripts in the context of present interactome knowledge, using Ingenuity Pathways Analysis tools. Using gene ontology analysis, closer examination of the genes resulted in a variety of 372 and 523 mutually-dependent molecular functions to be identified in $\mathrm{AC}$ and SCC, respectively; this evaluation revealed that the functional profiling was not randomly distributed, as shown in Fig. 1C (P-value for all <0.05). Significantly downregulated 
A

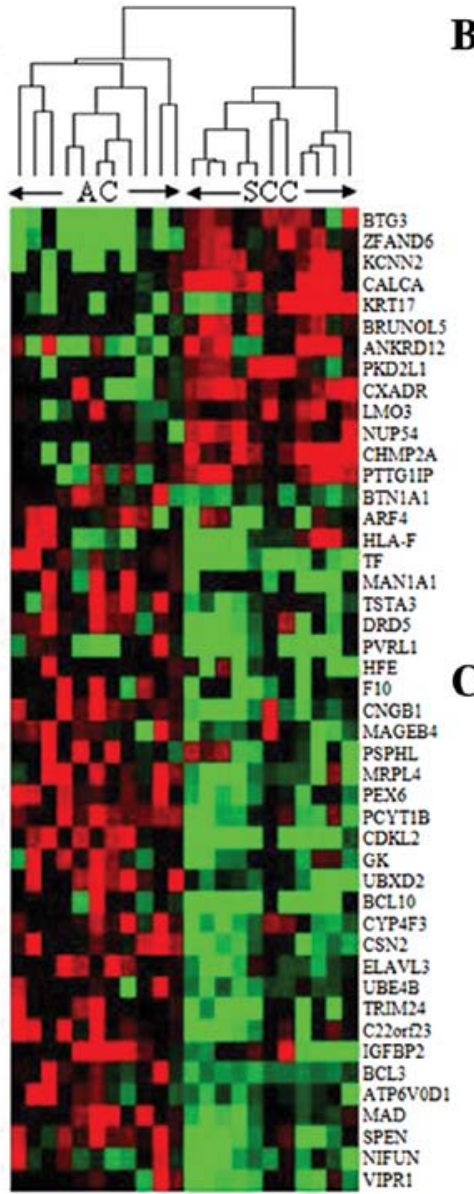

B

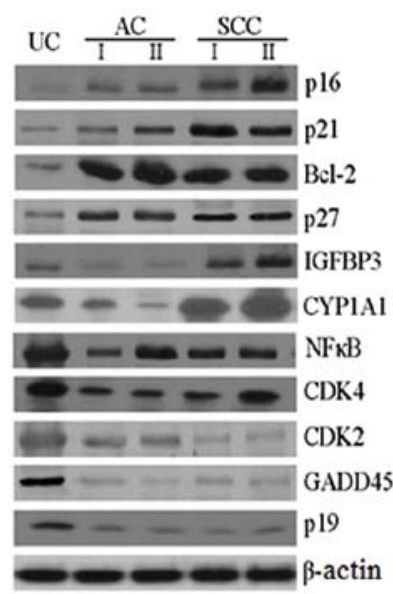

D

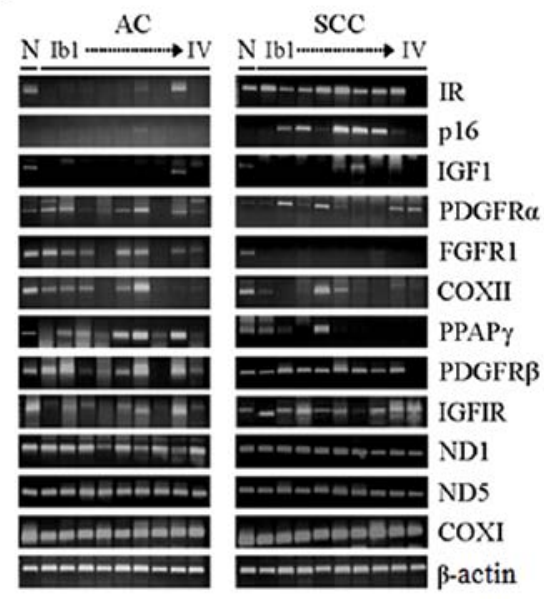

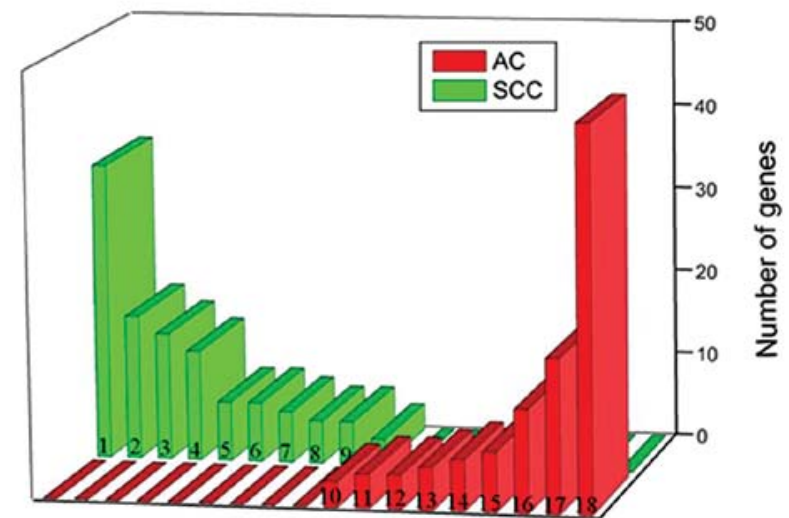

Figure 1. Gene expression profiles measured by microarrays. (A) Hierarchical clustering analysis in AC and SCC. A dendrogram (tree graph) shows the grouping of the genes based on the similarity between them. Supervised analysis of 46 transcripts was carried out using the 'Euclidean distance' to determine the similarity measure and the input rank as the ordering function (green, underexpression; red, overexpression). Dendrogram with tissues labels corresponding to the experiments. (B) Western blot analysis of differentially expressed genes of the microarray. Columns refer to common reference (N) and each cancer stage (I and II). (C) Differential display of key functional patterns between AC and SCC (P-value for all <0.05). Representative functional clusters were obtained using Gene Ontology analysis based on cluster visualization. (1) Apoptosis of neurons, (2) cell death of pheochromocytoma cells, (3) damage to DNA, (4) binding of synthetic promoter, (5) polyploidization, (6) proliferation of granulocytes, (7) differentiation of erythroid progenitor cells, (8) emigration of T lymphocytes, (9) colony formation of colony-forming erythroid cells, (10) internalization of virus, (11) anoikis of epithelial cells, (12) proliferation of ovarian cancer cells, (13) G1 phase of epithelial cells, (14) stabilization of mitochondrial membrane, (15) binding of red blood cells, (16) splenomegaly, (17) hepatic system disorder and (18) immunological disorder. The differential clusters include several functions of the core enzyme activity, as well as several related families that share similar phenotypes. (D) Carcinogenesis-related transcripts by RT-PCR analysis. Total RNAs obtained from common reference RNAs (lane 1) and cervical cancer stages (lanes 2-9) were subjected to RT-PCR.

molecular functions for SCC were cell death in pheochromocytoma cells $(\mathrm{P}=0.0037)$, apoptosis in neurons $(\mathrm{P}=0.009)$ and damage to DNA $(\mathrm{P}=0.0038)$. The upregulated molecular function was internalization of virus $(\mathrm{P}=0.0091)$. By contrast, the upregulated molecular functions for $\mathrm{AC}$ were immunological disorder $(\mathrm{P}=0.006)$, splenomegaly $(\mathrm{P}=0.0053)$ and hepatic system disorder $(\mathrm{P}=0.006)$. Of note, the internalization of virus with viral infection (BCAR1, CSF2RA, LDLR) was clearly upregulated for both SCC $(\mathrm{P}=0.0091)$ and AC $(\mathrm{P}=0.0085)$. In Tables I and II, differentially up- or downregulated putative cervical cancer-network processes are summarized according to biological pathways. To detect the differences in the functional profiles between AC and SCC, we placed differentially expressed transcripts in the context of present interactome knowledge, using the Ingenuity Pathways Analysis tools ( $\mathrm{P}$-value for all $<0.05)$. Biologic pathway analysis revealed the antigen presenting canonical pathway
$(\mathrm{P}=0.03)$ as a significant molecular pathway in AC. Network analysis, based on predetermined knowledge on individually modeled relationships between genes, identified seven highly significant, overlapping networks in the data set. The topscoring network, built around the antigen presenting pathway, displayed high-level functions in the apoptosis signaling, GM-CSF signaling, death receptor signaling and PI3k/AKT signaling pathways. By contrast, the pathway analysis revealed the G2/M DNA damage checkpoint regulation pathway $(\mathrm{P}=0.05)$ as a significant molecular pathway in SCC. Network analysis identified highly significant overlapping of the networks. The top-scoring network displayed high-level functions in the estrogen receptor signaling, Notch signaling, death receptor signaling and apoptosis signaling pathways. The relative expression of the transcripts SPEN, HLA-DRB3, CDKN1A, MDM2 and TAF5L showed a correlation of the expression levels revealed by the microarray. 
Table I. Functional network analysis based on the transcript signature in AC.

\begin{tabular}{|c|c|c|c|c|c|}
\hline $\begin{array}{c}\text { Network } \\
\text { no. }\end{array}$ & Genes in the network & Score $^{a}$ & $\begin{array}{l}\text { High-level } \\
\text { functions }\end{array}$ & $\begin{array}{l}\text { No. of } \\
\text { associated } \\
\text { genes }^{\mathrm{b}}\end{array}$ & Significance $^{c}$ \\
\hline 1 & $\begin{array}{l}A P A F 1, A R H G A P 1, \text { BBC3, BCL2, BCL } 2 L 1, \\
B C L 2 L 10, C L C N 3, D C X, \text { DDR1, DNAJA3, } \\
F B X O 2, \text { HAP1, IGFBP6, ITPR } 1 \text {, L1CAM, } \\
\text { MRAS, NFKBIB, NRP1, PDCD2, PRDX1, } \\
R A S A 1, \text { RASGRP2, RIN1, RRAS, RRAS } 2, \\
\text { SCN3A, SEMA3F, SERPINF1, SKP1A, SNAP91, } \\
\text { SRP72, STAT6, TBX } 5, T X N I P, \text { WISP1 }\end{array}$ & 35 & $\begin{array}{l}\text { Cancer } \\
\text { Cell morphology } \\
\text { Cell death }\end{array}$ & $\begin{array}{l}24 \\
17 \\
21\end{array}$ & $\begin{array}{l}1.6 \mathrm{E}^{-8}-7.6 \mathrm{E}^{-3} \\
1.6 \mathrm{E}^{-8}-7.6 \mathrm{E}^{-3} \\
1.5 \mathrm{E}^{-7}-7.6 \mathrm{E}^{-3}\end{array}$ \\
\hline 2 & $\begin{array}{l}\text { ALAS2, ARNT, } C B X 1 \text {, CHAF1B, } C S F 2 R A, \text { DDB2, } \\
\text { DNAJB1, FANCA, } F A N C C, \text { G1P3, IER3, IFNA6, } \\
\text { IL12RB1, } I L 12 R B 2, \text { IL27RA, ING1, IRF3, JAK2, } \\
L B P, \text { PGK1, } P M L, \text { REST, SAP30, SF3A1, SF3A3, } \\
\text { SH2B, SIM2, SKI, SMARCC1, STAT1, } T B K 1, \text { TIF1, } \\
\text { TRIM28, ZNF74, ZNF197 }\end{array}$ & 35 & $\begin{array}{l}\text { Gene expression } \\
\text { Cell death } \\
\text { immunological } \\
\text { disease }\end{array}$ & $\begin{array}{l}22 \\
21 \\
11\end{array}$ & $\begin{array}{l}8.7 \mathrm{E}^{-8}-3.0 \mathrm{E}^{-2} \\
4.0 \mathrm{E}^{-7}-3.0 \mathrm{E}^{-2} \\
4.0 \mathrm{E}^{-7}-3.3 \mathrm{E}^{-2}\end{array}$ \\
\hline 3 & $\begin{array}{l}\text { B2M, BCL3, BOK, CDH4, CDKL2, CLU, COL } 1 A 2, \\
C O P S 2, \text { COPS5, } C Y R 61, E E F 1 A 1, E I F 3 S 6, \text { FUS, } \\
G 22 P 1, \text { GCNT2, GDF }, \text { HCST, } H N R P C, \text { HNRPU, } \\
I L F 3, \text { JUND, } K I R 3 D L 1, \text { KLRC2, } K L R C 3, L I G 3, \\
\text { MAN1B1, MCL } 1, \text { MIF, } M L F 1, N R G 1, \text { PDE3A, } \\
\text { RFX5, TF, TYROBP, VAV1 }\end{array}$ & 35 & $\begin{array}{l}\text { Cell death } \\
\text { Cancer } \\
\text { DNA replication }\end{array}$ & $\begin{array}{l}20 \\
19 \\
10\end{array}$ & $\begin{array}{l}6.9 \mathrm{E}^{-6}-2.5 \mathrm{E}^{-2} \\
1.8 \mathrm{E}^{-5}-2.3 \mathrm{E}^{-2} \\
2.8 \mathrm{E}^{-5}-2.2 \mathrm{E}^{-2}\end{array}$ \\
\hline 4 & $\begin{array}{l}\text { ADORA2B, ANXA4, BAIAP2, CCND2, CCNE1, } \\
\text { CCR5, CDT1, CUL3, EDNRA, ELL, ERG, FOS, } \\
\text { HOXB4, KRT8, LDHA, LDHB, MLLT7, MXD1, } \\
\text { NCKAP1, NMB, PCDHGC3, PSMA2, PSMA5, } \\
\text { PSMA6, PSMB3, PSMC5, PSMD6, RBP1, } \\
\text { RPS6KA4, SFRP4, SLC } 19 A 1, \text { SOD1, TACR1, } \\
\text { VIL2, WASF2 }\end{array}$ & 35 & $\begin{array}{l}\text { Cell death } \\
\text { Cellular } \\
\text { development } \\
\text { Hematological } \\
\text { system }\end{array}$ & $\begin{array}{l}18 \\
14\end{array}$ & $\begin{array}{l}1.07 \mathrm{E}^{-4}-2.06 \mathrm{E}^{-2} \\
2.13 \mathrm{E}^{-4}-3.03 \mathrm{E}^{-2} \\
2.13 \mathrm{E}^{-4}-1.91 \mathrm{E}^{-2}\end{array}$ \\
\hline 5 & $\begin{array}{l}\text { ACVR2B, AUP1, } B R S 3, C A V 1, C D 9, \text { CD47, } \\
C D 151, C O L 6 A 2, \text { CSK, CSPG2, } C T S K, \text { DAG1, } \\
\text { EGFR, ELN, ERBB2, FBLN2, GNAS, } \\
G N R H R, H T R 4, \text { ITzNF4A, IFITM1, MUC6, } \\
\text { NAP1L1, PHLDA2, PPARG, PRG4, PTPRU, } \\
S P A G 11, S U F U, \text { TAX1BP3, TDGF1, TRERF1 }\end{array}$ & 35 & $\begin{array}{l}\text { Cell-to-cell } \\
\text { signaling and } \\
\text { Gene expression } \\
\text { Cancer } \\
\text { Cellular growth } \\
\text { and proliferation }\end{array}$ & $\begin{array}{l}20 \\
19 \\
20\end{array}$ & $\begin{array}{l}1.9 \mathrm{E}^{-7}-3.8 \mathrm{E}^{-3} \\
6.9 \mathrm{E}^{-11}-3.8 \mathrm{E}^{-3} \\
8.9 \mathrm{E}^{-10}-3.8 \mathrm{E}^{-3} \\
8.9 \mathrm{E}^{-10}-3.8 \mathrm{E}^{-3}\end{array}$ \\
\hline
\end{tabular}

Bold type indicates genes of the test set that were overexpressed in AC. Genes that were underexpressed in AC are indicated as italic. No. of genes identified as part of the test set mapping to the network. ${ }^{a}$ Reflects the negative logarithm of the P-value that indicates the likelihood of the focus genes in a network being found together as a result of random chance ( $99 \%$ confidence level; scores $\geq 2$ were considered significant). ${ }^{b} \mathrm{No}$. of genes significantly associated with the corresponding high-level function. ${ }^{\mathrm{C}}$ Range of significances of the associated genes for the high-level function $(\alpha=0.05)$.

Correlation of canonical pathway and carcinogenesis-related genes. We searched the carcinogenesis-related transcript expression patterns for interaction of additional members of these putative pathways. Although none existed in the microarray, the expression patterns of additional carcinogenesis-related genes were observed in our model. As shown in Fig. 1D, the differential transcript expressions are shown for SCC and AC. The overexpressed transcripts in SCC were IR, p16, IGF1, IGF1R, PDGFR $\alpha$ and PDGFR $\beta$. By contrast, the overexpressed transcripts in AC were PDGFR $\alpha$, FGFR1, PPAR $\gamma$ and PDGFR $\beta$. Differential expression of the trans- cripts could be related to the tumor classification. The ND1, ND5 and COX1 showed no differential expression patterns. The antigen presenting canonical pathway was revealed to be linked to PPAR $\gamma$ in AC. The overexpression of this gene was observed to be related to HLA-DRA overexpression in the pathway as shown in Fig. 2. In addition, the overexpression of the PPAR $\gamma$ and HAL-DRA was significantly associated with NEUROG3 overexpression. This analysis included complete overexpression of the PPAR $\gamma$ gene in AC from stage Ibla to IV. The G2/M DNA damage checkpoint regulation pathway was observed to be significantly linked to IGF1R in SCC. The 
Table II. Functional network analysis based on the transcript signature in SCC.

\begin{tabular}{|c|c|c|c|c|c|}
\hline $\begin{array}{l}\text { Network } \\
\text { no. }\end{array}$ & Genes in the network & Score $^{\mathrm{a}}$ & $\begin{array}{l}\text { High-level } \\
\text { functions }\end{array}$ & $\begin{array}{l}\text { No. of } \\
\text { associated } \\
\text { genes }^{\mathrm{b}}\end{array}$ & Significance $^{c}$ \\
\hline \multirow[t]{3}{*}{1} & \multirow{3}{*}{$\begin{array}{l}A D D 1, \text { ANXA5, CBX4, CCRK, CDK2, CDK7, } \\
\text { CDKN1A, CYR61, DYRK1B, EXO1, FHL1, } \\
\text { FOXG1B, GTF2H2, HES1, LOC58486, MAML1, } \\
M C M 4, \text { MCM6, MFNG, MLLT7, MNAT1, MS4A3, } \\
\text { PCGF4, PCGF6, PLK2, PPP1R } 12 A, P P P 1 R 12 B, \\
\text { RBL2, RBPSUH, ROCK2, RRM1, RRM2, } \\
\text { SART2, SPEN, STSSIA1 }\end{array}$} & \multirow[t]{3}{*}{36} & Cell cycle & 14 & $4.2 \mathrm{E}^{-6}-2.2 \mathrm{E}^{-2}$ \\
\hline & & & Gene expression & 13 & $5.4 \mathrm{E}^{-6}-1.9 \mathrm{E}^{-2}$ \\
\hline & & & Cancer & 13 & $6.1 \mathrm{E}^{-6}-2.2 \mathrm{E}^{-2}$ \\
\hline \multirow[t]{3}{*}{2} & \multirow{3}{*}{$\begin{array}{l}A P A F 1, \text { APPL, BAX, BBC3, BCL2L1, BFAR, } \\
B N I P 1, C A L B 1, \text { CASP1, CASP } 3, C A S P 8, C A S P 10, \\
C F L A R, C H S T 8, D C C, E I F 4 A 2, E I F 4 G 3, H S P B 2, \\
I F I 16, I L 18, I T P R 1, M A D D, M D M 2, \text { NALP1, } \\
\text { NOL3, NUMB, PPP1CA, PRNP, PTGS2, RIPK1, } \\
\text { RIPK4, SEPT4, SNCB, TRAF1, TRIP }\end{array}$} & \multirow[t]{3}{*}{36} & Cell death & 30 & $2.6 \mathrm{E}^{-17}-3.8 \mathrm{E}^{-3}$ \\
\hline & & & Cancer & 22 & $9.8 \mathrm{E}^{-15}-3.8 \mathrm{E}^{-3}$ \\
\hline & & & $\begin{array}{l}\text { Hematological } \\
\text { disease }\end{array}$ & 13 & $5.5 \mathrm{E}^{-11}-3.8 \mathrm{E}^{-3}$ \\
\hline \multirow[t]{3}{*}{3} & $\begin{array}{l}A D R A 1 D, A T P 2 B 4, B D P 1 \text {, BRF1, BST2, CEBPZ, } \\
C H R N A 5, D D X 20, \text { EGR3, FGF9, GEMIN } 4, G L D C \text {, }\end{array}$ & \multirow[t]{3}{*}{36} & $\begin{array}{l}\text { Cellular assembly } \\
\text { and organization }\end{array}$ & 11 & $1.4 \mathrm{E}^{-5}-4.8 \mathrm{E}^{-2}$ \\
\hline & GSTM5, GTF3C1, GTF3C4, HOXB4, LAMB3, & & Cancer & 7 & $2.1 \mathrm{E}^{-4}-4.8 \mathrm{E}^{-2}$ \\
\hline & $\begin{array}{l}\text { MEST, MICB, MTA2, PAX3, PKIA, PTPN14, } \\
R B 1, \text { SMC1L1, STAG3, STX } 3 A, \text { SYBL1, TM } 4 S F 2, \\
T M P O, T O P 2 A, T O P 2 B, T R I P 11, \text { TSPY1, YWHAE }\end{array}$ & & Cell cycle & 9 & $2.1 \mathrm{E}^{-4}-4.8 \mathrm{E}^{-2}$ \\
\hline \multirow[t]{3}{*}{4} & $A C A D M$, APOA1, APOA2, $A T P 2 B 1$, BCAR1, & \multirow[t]{3}{*}{36} & Cellular movement & 19 & $1.2 \mathrm{E}^{-9}-7.6 \mathrm{E}^{-3}$ \\
\hline & CAPN3, $C C L 8, \mathbf{C C L 2 7}, C C R L 1, \mathbf{C D 3 3}, C D 36$, & & Cancer & 16 & $2.4 \mathrm{E}^{-9}-7.6 \mathrm{E}^{-3}$ \\
\hline & $\begin{array}{l}\text { CDK5R1, CXCL12, CXCL16, CXCR6, CYP3A5, } \\
D C X, \text { FOXA3, IFNAR1, IL12B, ISGF } 3 G, I T G A V, \\
\text { ITGB3, L1CAM, } L T F, P C T K 1, P H K A 2, \text { PLCB1, } \\
P P A P 2 B, R A L A, S E C 10 L 1, S E C 8 L 1, S E P T 7, \\
S T A T 2, \text { TNFRSF8 }\end{array}$ & & $\begin{array}{l}\text { Immunological } \\
\text { disease }\end{array}$ & 7 & $4.7 \mathrm{E}^{-8}-3.8 \mathrm{E}^{-3}$ \\
\hline \multirow[t]{3}{*}{5} & \multirow{3}{*}{ 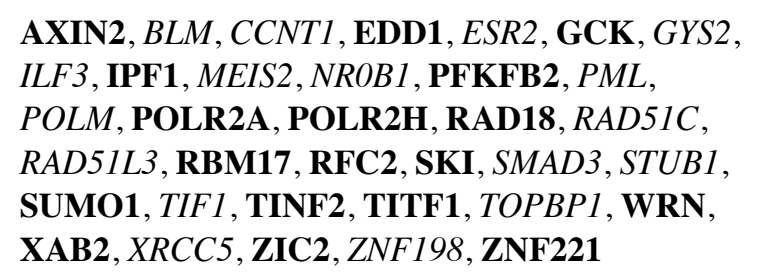 } & \multirow[t]{3}{*}{36} & Gene expression & 19 & $8.7 \mathrm{E}^{-8}-3.4 \mathrm{E}^{-2}$ \\
\hline & & & DNA replication & 10 & $4.5 \mathrm{E}^{-6}-3.4 \mathrm{E}^{-2}$ \\
\hline & & & Cell cycle & 10 & $6.0 \mathrm{E}^{-6}-3.2 \mathrm{E}^{-2}$ \\
\hline \multirow[t]{3}{*}{6} & $\begin{array}{l}\text { ADCY5, ATF7, BMP2, BRAF, CNKSR1, GAS, } \\
G N B 5, \text { MAP3K6, MAPK7, MAP } 9, M A P K 10,\end{array}$ & \multirow[t]{3}{*}{19} & $\begin{array}{l}\text { Amino acid } \\
\text { metabolism }\end{array}$ & 9 & $2.1 \mathrm{E}^{-6}-3.8 \mathrm{E}^{-3}$ \\
\hline & $\begin{array}{l}\text { MEF2C, } M I N K 1 \text {, MRAS, } M Y L K, \text { NTRK3, } P L N \text {, } \\
\text { RASGRP2, RGS9, SCNN } 1 A, S G K, \text { SLC18A2, }\end{array}$ & & $\begin{array}{l}\text { Post-translational } \\
\text { modification }\end{array}$ & 8 & $2.1 \mathrm{E}^{-6}-1.2 \mathrm{E}^{-3}$ \\
\hline & TBX5, TNFRSF11B, TNIK, WWP2 & & $\begin{array}{l}\text { Small molecule } \\
\text { biochemistry }\end{array}$ & 17 & $2.1 \mathrm{E}^{-6}-3.1 \mathrm{E}^{-2}$ \\
\hline \multirow[t]{3}{*}{7} & $\begin{array}{l}76 P, A C B D 3, A K 3, A K A P 9, C D 276, C O I L, \\
I L 12 R B 2, I L 17 E, I L 8 R A, K L R D 1, M A P K 14,\end{array}$ & \multirow[t]{3}{*}{10} & $\begin{array}{l}\text { Cellular assembly } \\
\text { and organization }\end{array}$ & 12 & $3.4 \mathrm{E}^{-11}-3.8 \mathrm{E}^{-3}$ \\
\hline & $\begin{array}{l}\text { NOLC1, NUP155, PCNT2, POLE2, POLE3, } \\
\text { PRKCBP1, PTPN4, SNCB }\end{array}$ & & $\begin{array}{l}\text { Cellular function } \\
\text { and maintenance }\end{array}$ & 9 & $1.8 \mathrm{E}^{-9}-3.8 \mathrm{E}^{-3}$ \\
\hline & \multirow{4}{*}{$\begin{array}{l}A L D O B, A P O M, B Z R A P 1, C D 1 B, C Y P 11 A 1, \\
E S R 2, \text { GAPD, HNF4A, IFI30, KCNJ11, NOS2A, } \\
N R O B 2, N R 1 I 2, S M A D 3, S T A M B P \\
T M 7 S F 2, W W P 1\end{array}$} & & Cellular development & 6 & $1.0 \mathrm{E}^{-6}-3.8 \mathrm{E}^{-3}$ \\
\hline \multirow[t]{3}{*}{8} & & \multirow[t]{3}{*}{8} & $\begin{array}{l}\text { Amino acid } \\
\text { metabolism }\end{array}$ & 23 & $4.7 \mathrm{E}^{-12}-7.6 \mathrm{E}^{-3}$ \\
\hline & & & $\begin{array}{l}\text { Post-translational } \\
\text { modification }\end{array}$ & 18 & $3.9 \mathrm{E}^{-8}-7.6 \mathrm{E}^{-3}$ \\
\hline & & & $\begin{array}{l}\text { Small molecule } \\
\text { biochemistry }\end{array}$ & 15 & $3.9 \mathrm{E}^{-8}-7.6 \mathrm{E}^{-3}$ \\
\hline
\end{tabular}

Bold type indicates genes of the test set that were overexpressed in SCC. Genes that were underexpressed in SCC are indicated as italic. a-c, same as in Table I legend. 


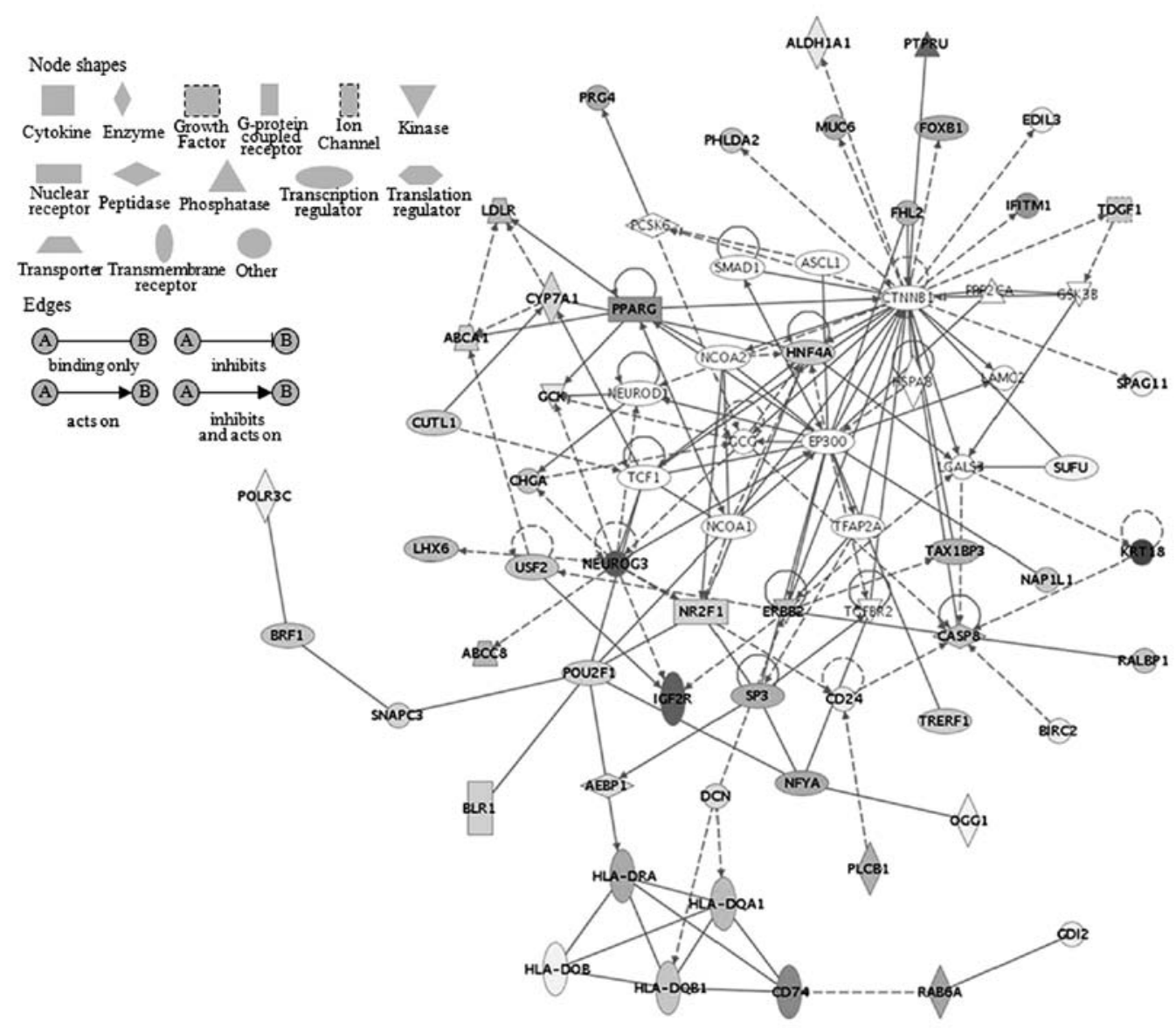

Figure 2. Biological pathway-based gene expression. Network mapping of genes with $>2$-fold expression change using Ingenuity Pathway Analysis (IPA). PPAR $\gamma$ and MHC class II (HLA-DRA, DPA1, DQA1 and DQB1) connect the top 2 networks in AC. Light gray indicates downregulation and dark gray indicates upregulation, with the more intense shade indicating a greater change. Gene names are indicated. A line indicates that 2 genes products have shown binding, a line terminating in an arrow means 1 gene product acts on the other gene product, and a plus symbol indicates other networks contain the gene product.

upregulation of this gene was noted to be related to YWHAE and TOP2A downregulation in the pathway (Fig. 3). In addition, the upregulation of IGF1R was significantly associated with RB1 downregulation. This analysis included the upregulation of the IGF1R gene in SCC from stage Ib1 to IVb. Therefore, the molecular pathways of SCC and AC appear to be related to different carcinogenesis-related genes resulting from cell transformation.

\section{Discussion}

The specific details of the reference RNA, as a control, from several cell lines or tissues have previously been reported (8). The properties of a cell line derived reference RNA sample has failed to address the long-term needs and highly reproducible reference samples (9). Immortal cell lines are obviously not normal. In this study, we show that a well maintained reproducible reference sample can be created from a pool of RNAs derived from normal cervixes. Comparison of two duplicate samples demonstrated the reproducibility of this experimental approach (correlation coefficient $>0.95$ ).

Even though the overall signal patterns found on the $\mathrm{AC}$ and SCC hybridized arrays were similar, a small subset of regions showed differential expression signals in comparisons between the AC and SCC. Using hierarchical clustering, 46 transcripts separated the samples into two distinct groups on the basis of the expression patterns. Therefore, these genes can be characterized as new putative histology-specific cervical cancer genes. KRT17 is coexpressed with KRT16 only in pathological situations such as metaplasia and carcinoma of the uterine cervix as well as in psoriasis vulgaris (10). It was noted that KRT17 showed increased gene expression only in SCC specimens. This is compatible with the previous finding that during progression of cervical intraepithelial neoplasia a clear increase in the expression of keratin 17 was observed (11). The IGFBP2 transcript was significantly increased in high grade prostate intraepithelial neoplasia (PIN) and adenocarcinoma (12). A significant overexpression of IGFBP2 was observed in patients with localized prostate adenocarcinoma; this suggests that overexpression of IGFBP2 is a powerful marker for malignant transformation in prostate epithelium. IGFBP2 was only downregulated in SCC in this study. In the case of VIPR1, the normalized overexpression distribution for tissue type (http://genome-www5.stanford. edu/cgi-bin/source/sourceSearch) was $13.7 \%$ in the adrenal gland, and only expressed in AC in this study. VIPR1 has been characterized and localized in the neoplastic cells of most adenocarcinomas such as ovarian adenocarcinomas, colonic adenocarcinomas and pancreatic adenocarcinomas (13). Future studies are needed to clarify the regulatory mechanisms of these 46 genes and their role in AC and SCC. 


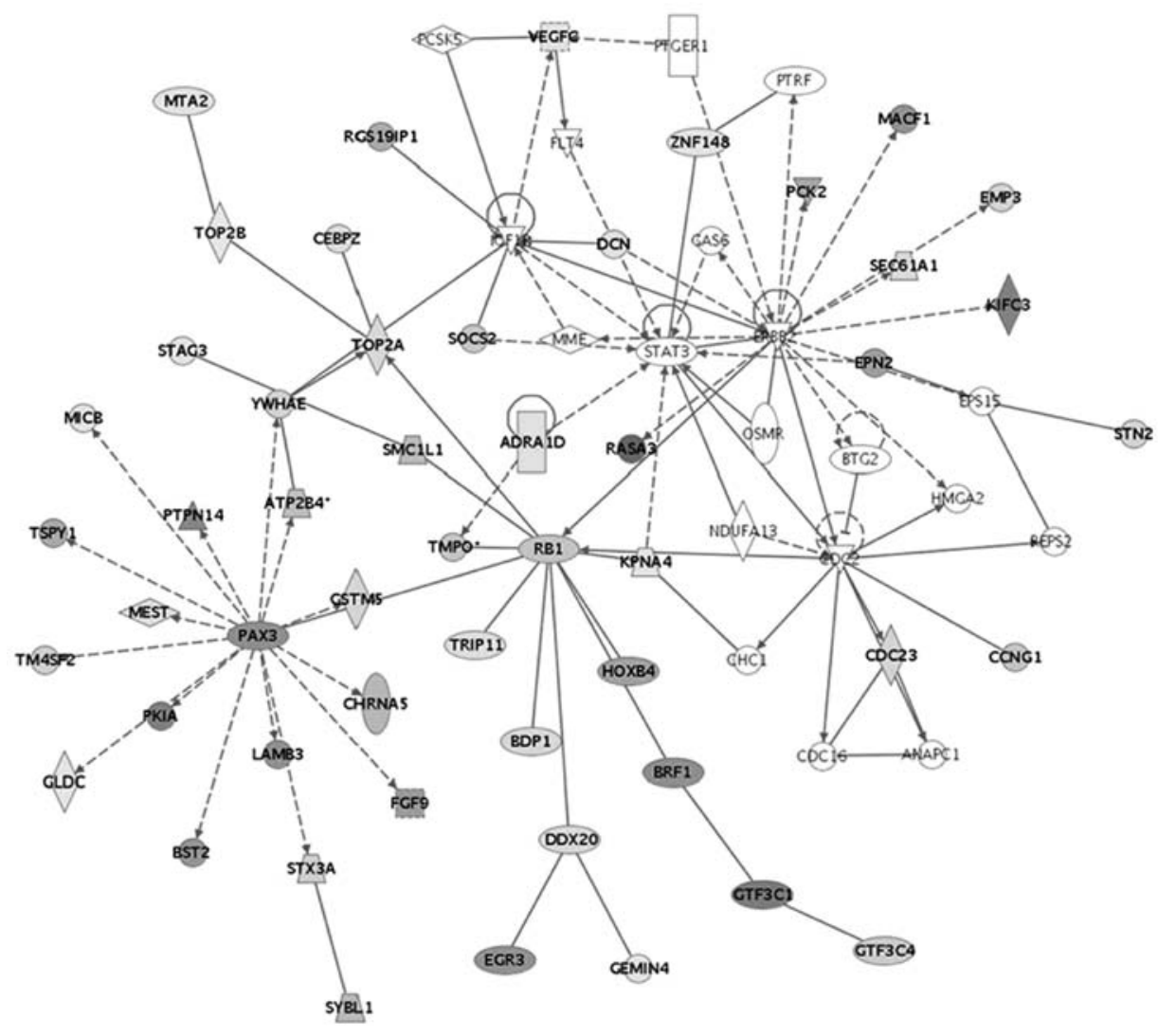

Figure 3. Biological pathway-based gene expression. Network mapping of genes with $>2$-fold expression change. IGF1R and YWHAE connect the top 2 networks in SCC. The symbols are the same as in Fig. 2.

Combined application of our network analysis of differentially regulated genes in AC and SCC revealed that most of the genes were assigned to tens of the cellular processes $(\mathrm{P}<0.05)$, revealed as key functions of a variety of cellular activities involved in cervical carcinogenesis. Genes (BCAR1, CSF2RA and LDLR) associated with internalization of virus functions $(\mathrm{P}=0.0091)$ were commonly overexpressed in both $\mathrm{AC}$ and SCC. We also observed significant upregulated functions associated with immunological $(\mathrm{P}=0.006)$, hepatic system $(\mathrm{P}=0.006)$ and splenomegaly $(\mathrm{P}=0.0053)$ disorders in AC. The genes coding for 32 out of 45 immunological disorder functions were upregulated; this finding suggests the importance of these gene products in the developmental pathway of cervical adenocarcinoma. In addition, the genes coding for 9 out of 12 splenomegaly immune diseases were upregulated. It has been reported that the hepatic changes, as well as marked splenomegaly, may represent an altered immunophenomenon of uterine cervical cancer (14). Numerous genes coding for proteins involved in immunological disorders were notably upregulated in AC. In several types of carcinoma, a number of genes responsible for the immune response have been reported to be upregulated (15). By contrast, the significant downregulated functions observed in SCC were apoptosis of neurons $(\mathrm{P}=0.009)$, cell death of pheochromocytoma cells $(\mathrm{P}=0.006)$ and damage to DNA $(\mathrm{P}=0.0057)$. The genes coding for 25 out of 35 apoptosis of neuron function were downregulated. In addition, the genes coding for 13 out of 15 damage to DNA function were downregulated; this suggests the importance of these gene products in the developmental pathway of squamous cell cervical carcinoma. Disruption of apoptosis and the cell cycle progression pathways has been implicated in abnormal cell growth and carcinogenesis (16). We observed that genes involved in cell death were significantly downregulated in SCC compared to AC.

In this study our investigation focused on the main molecular pathway of SCC and AC, and its involvement in response to carcinogenesis and cell transformation. The functional profiling consequence of SCC and AC was the G2/M DNA damage checkpoint regulation pathway and antigen presenting pathway, respectively. The DNA damage-induced cell cycle checkpoint has broad implications for human disease, particularly cancer (17). The G2/M cell cycle checkpoint is especially emerging as an attractive candidate for new cancer therapies (18). The G2/M checkpoint prevents cells from attempting to undergo mitosis in an inappropriate state; due to defects in G1 checkpoint mechanisms, cancer cells depend on the G2/M checkpoint far more than normal cells and it suggested that therapeutic agents acting at this cell cycle phase may confer tumor selectivity. p53 can regulate the G2/M transition either through the induction of $\mathrm{p} 21$ and $14-3-3 \sigma$, a protein that normally sequesters cyclin B1-Cdc2 complexes in the cytoplasm or through the induction of apoptosis (19). The human papilloma virus E6 protein (HPV-E6) appears to allow genetic or epigenetic events to occur that severely impair the G2 checkpoint by binding and inactivating of p53 that is required for G2 arrest. The different observations made with HPV-E6 and the truncated form of p53 suggests that other targets of HPV-E6 may contribute to the G2 checkpoint (20). 
The expression patterns of the carcinogenesis-related genes were different in the comparisons between SCC and AC. The overexpressed transcripts in SCC, such as p16, IGF1 and PDGFR $\alpha$ were reported previously (21). By contrast, the overexpressed transcripts in AC were PDGFR $\alpha$, PPAR $\gamma$ and PDGFR $\beta$ (22). The G2/M DNA damage checkpoint regulation pathway in SCC was observed to be significantly linked to IGF1R via YWHAE protein-protein interaction (23). IGF-I and IGF-IR are known to play an important role in cell transformation induced by viral oncogenes, such as E6 and E7 (24). It has been reported that YWHAE (14-3-3 proteins) interacts with IGFIR in vivo and that this interaction may play a role in a transformation pathway signaled by the IGFIR (25). The 14-3-3 proteins are found in all eukaryotic cells and have been shown to bind to molecules involved in cell cycle control, apoptosis and oncogenesis (26). Overexpression of 14-3-3 caused most cells to arrest in G2. However, binding of 14-3-3 to phosphoserine 1283, in IGFIR, may play a role in IGFIR mediated transformation. In this study, the analysis included upregulation of the IGF1R transcript in SCC stage. It has also been reported that 14-3-3 proteins do not bind to the insulin receptor (IR) and the IR does not cause transformation (27). In addition, the upregulation of IGF1R was significantly associated with the downregulation of RB1. Rb family members are required to downregulate $\mathrm{Cdc} 2$ and Cyclin $\mathrm{B} 1$, which is necessary to maintain prolonged $\mathrm{G} 2$ arrest.

Malignant transformation is frequently associated with escape of tumor cells from immune recognition. The present study showed that the antigen presenting canonical pathway was observed to be linked to peroxisome proliferator-activated receptor gamma (PPAR $\gamma$ ) in AC in response to cell transformation. The overexpression of PPAR $\gamma$ has been related to MHC class II (HLA-DRA, DPA1, DQA1 and DQB1 overexpression) in this pathway. It has been shown that expression of PPAR $\gamma$ protein was higher in an adenocarcinoma cell line (TE-7 cells) than in a squamous cell carcinoma cell line (TE-1 cells) (28). PPAR $\gamma$ activation has been implicated in tumor promotion, cellular differentiation and apoptosis (29). Many of the effects of PPAR $\gamma$ are mediated through the inhibition of proinflammatory transcription pathways such as NF- $\mathrm{KB}, \mathrm{AP}-1$, NFAT, C/EBP or Smad3, via protein-protein interaction and competition for cofactor recruitment (30). The downregulation of IFN $\gamma$ and IL-12 by PPAR $\gamma$ is known to prevent the development of inflammatory diseases (31). In addition, the effects of PPAR $\gamma$ on dendritic cells can drive the local immune response by favoring the differentiation of $\mathrm{TH} 2$ cells, thus orienting the immune response toward a humoral response. In human $\mathrm{T}$ cells, PPAR $\gamma$ activators reduce the secretion of IFN $\gamma, \mathrm{TNF} \alpha$ and IL-2 (32). These data suggest an important role of PPAR $\gamma$ in $\mathrm{AC}$ and the immune system with a potential profound impact on the immune response. It has been reported that metabolites that physically binds to PPAR $\gamma$ as a ligand leads to apoptosis of lung adenocarcinoma cells, and this may be beneficial for the therapy of such cancers (33). Understanding the role of IGF1R and PPAR $\gamma$ in cervical carcinogenesis is important for designing diagnostic and therapeutic interventions as well as future research (34).

In this study, microarray data and knowledge-based information analyses were used for tumor classification. Different expression profiles of genes and their specific molecular networks were involved in the progression associated with SCC and AC. In addition, we identified the utilization of the G2/M DNA damage checkpoint regulation pathway in SCC and the antigen presenting canonical pathway in AC. Therefore, good candidate genes identified from this study clearly displayed specific association with each aggressive biological subset of cervical cancer. Further studies can be carried out to identify tumor markers that may be useful for patient diagnosis and treatment of SCC and AC.

\section{Acknowledgements}

The study was supported by the National Research Foundation of Korea (NRF), Seoul, Republic of Korea (Grant no. 5-2011A0154-00120). The funders had no role in study design, data collection and analysis, decision to publish or preparation of the manuscript.

\section{References}

1. Bulk S, Visser O, Rozendaal L, Verheijen RH and Meijer CJ: Cervical cancer in the Netherlands 1989-1998: decrease of squamous cell carcinoma in older women, increase of adenocarcinoma in younger women. Int J Cancer 113: 1005-1009, 2005.

2. International Collaboration of Epidemiological Studies of Cervical Cancer: Comparison of risk factors for invasive squamous cell carcinoma and adenocarcinoma of the cervix: collaborative reanalysis of individual data on 8,097 women with squamous cell carcinoma and 1,374 women with adenocarcinoma from 12 epidemiological studies. Int J Cancer 120: 885-891, 2007.

3. Ciapponi A, Bardach A, Glujovsky D, Gibbons L and Picconi MA: Type-specific HPV prevalence in cervical cancer and high-grade lesions in Latin America and the Caribbean: systematic review and meta-analysis. PLoS One 6: e25493, 2011.

4. Clifford GM, Smith JS, Plummer M, Munoz N and Franceschi S: Human papillomavirus types in invasive cervical cancer worldwide: a meta-analysis. Br J Cancer 88: 63-73, 2003.

5. Castellsague X, Diaz M, de Sanjose S, et al: Worldwide human papillomavirus etiology of cervical adenocarcinoma and its cofactors: implications for screening and prevention. J Natl Cancer Inst 98: 303-315, 2006.

6. Plummer M, Herrero R, Franceschi S, et al: Smoking and cervical cancer: pooled analysis of the IARC multi-centric case-control study. Cancer Causes Control 14: 805-814, 2003.

7. Wingo SN, Gallardo TD, Akbay EA, et al: Somatic LKB1 mutations promote cervical cancer progression. PLoS One 4: e5137, 2009.

8. Wessels JM, Edwards AK, Zettler C and Tayade C: Selection and validation of reference genes for miRNA expression studies during porcine pregnancy. PLoS One 6: e28940, 2011.

9. Yang IV, Chen E, Hasseman JP, et al: Within the fold: assessing differential expression measures and reproducibility in microarray assays. Genome Biol 3: research0062, 2002.

10. Bae SM, Lee CH, Cho YL, et al: Two-dimensional gel analysis of protein expression profile in squamous cervical cancer patients. Gynecol Oncol 99: 26-35, 2005.

11. Smedts F, Ramaekers F, Troyanovsky S, et al: Basal-cell keratins in cervical reserve cells and a comparison to their expression in cervical intraepithelial neoplasia. Am J Pathol 140: 601-612, 1992.

12. Zumkeller W: IGFs and IGFBPs: surrogate markers for diagnosis and surveillance of tumour growth? Mol Pathol 54: 285-288, 2001.

13. Reubi JC: In vitro identification of vasoactive intestinal peptide receptors in human tumors: implications for tumor imaging. J Nucl Med 36: 1846-1853, 1995.

14. Nakanuma Y, Kouda W, Nakano T, Uneno K, Tachibana S and Araki I: A case report of early idiopathic portal hypertension. Pathol Res Pract 197: 759-767, 2001.

15. Iizuka N, Oka M, Yamada-Okabe $\mathrm{H}$, et al: Comparison of gene expression profiles between hepatitis B virus- and hepatitis C virus-infected hepatocellular carcinoma by oligonucleotide microarray data on the basis of a supervised learning method. Cancer Res 62: 3939-3944, 2002. 
16. Wyllie AH: Apoptosis and carcinogenesis. Eur J Cell Biol 73: 189-197, 1997.

17. Dixon BP, Henry J, Siroky BJ, Chu A, Groen PA and Bissler JJ: Cell cycle control and DNA damage response of conditionally immortalized urothelial cells. PLoS One 6: e16595, 2011.

18. Luk SC, Siu SW, Lai CK, Wu YJ and Pang SF: Cell cycle arrest by a natural product via $\mathrm{G} 2 / \mathrm{M}$ checkpoint. Int J Med Sci 2: 64-69, 2005

19. Choi HJ, Fukui M and Zhu BT: Role of cyclin B1/Cdc2 up-regulation in the development of mitotic prometaphase arrest in human breast cancer cells treated with nocodazole. PLoS One 6: e24312, 2011.

20. Gao Q, Srinivasan S, Boyer SN, Wazer DE and Band V: The E6 oncoproteins of high-risk papillomaviruses bind to a novel putative GAP protein, E6TP1, and target it for degradation. Mol Cell Biol 19: 733-744, 1999.

21. Arai H, Ueno T, Tangoku A, et al: Detection of amplified oncogenes by genome DNA microarrays in human primary esophageal squamous cell carcinoma: comparison with conventional comparative genomic hybridization analysis. Cancer Genet Cytogenet 146: 16-21, 2003.

22. Schneider G, Weber A, Zechner U, et al: GADD45alpha is highly expressed in pancreatic ductal adenocarcinoma cells and required for tumor cell viability. Int J Cancer 118: 2405-2411, 2006.

23. Parvaresch S, Yesilkaya T, Baer K, Al-Hasani H and Klein HW: 14-3-3 binding to the IGF-1 receptor is mediated by serine autophosphorylation. FEBS Lett 532: 357-362, 2002.

24. Nakamura K, Hongo A, Kodama J, Miyagi Y, Yoshinouchi M and Kudo T: Down-regulation of the insulin-like growth factor I receptor by antisense RNA can reverse the transformed phenotype of human cervical cancer cell lines. Cancer Res 60: 760-765, 2000.

25. Spence SL, Dey BR, Terry C, Albert P, Nissley P and Furlanetto RW: Interaction of 14-3-3 proteins with the insulinlike growth factor I receptor (IGFIR): evidence for a role of 14-3-3 proteins in IGFIR signaling. Biochem Biophys Res Commun 312: 1060-1066, 2003.
26. Fu H, Subramanian RR and Masters SC: 14-3-3 proteins: structure, function, and regulation. Annu Rev Pharmacol Toxicol 40: 617-647, 2000.

27. Craparo A, Freund R and Gustafson TA: 14-3-3 (epsilon) interacts with the insulin-like growth factor I receptor and insulin receptor substrate I in a phosphoserine-dependent manner. J Biol Chem 272: 11663-11669, 1997.

28. Takashima T, Fujiwara Y, Higuchi K, et al: PPAR- $\gamma$ ligands inhibit growth of human esophageal adenocarcinoma cells through induction of apoptosis, cell cycle arrest and reduction of ornithine decarboxylase activity. Int J Oncol 19: 465-471, 2001.

29. Yang WL and Frucht H: Activation of the PPAR pathway induces apoptosis and COX-2 inhibition in HT-29 human colon cancer cells. Carcinogenesis 22: 1379-1383, 2001.

30. Hall JM and McDonnell DP: The molecular mechanisms underlying the proinflammatory actions of thiazolidinediones in human macrophages. Mol Endocrinol 21: 1756-1768, 2007.

31. Chawla A, Barak Y, Nagy L, Liao D, Tontonoz P and Evans RM: PPAR-gamma dependent and independent effects on macrophage-gene expression in lipid metabolism and inflammation. Nat Med 7: 48-52, 2001.

32. Marx N, Kehrle B, Kohlhammer K, et al: PPAR activators as antiinflammatory mediators in human T lymphocytes: implications for atherosclerosis and transplantation-associated arteriosclerosis. Circ Res 90: 703-710, 2002.

33. Shankaranarayanan P and Nigam S: IL-4 induces apoptosis in A549 lung adenocarcinoma cells: evidence for the pivotal role of 15-hydroxyeicosatetraenoic acid binding to activated peroxisome proliferator-activated receptor gamma transcription factor. J Immunol 170: 887-894, 2003.

34. Eichele K, Ramer R and Hinz B: R(+)-methanandamideinduced apoptosis of human cervical carcinoma cells involves a cyclooxygenase-2-dependent pathway. Pharm Res 26: 346-355, 2009. 